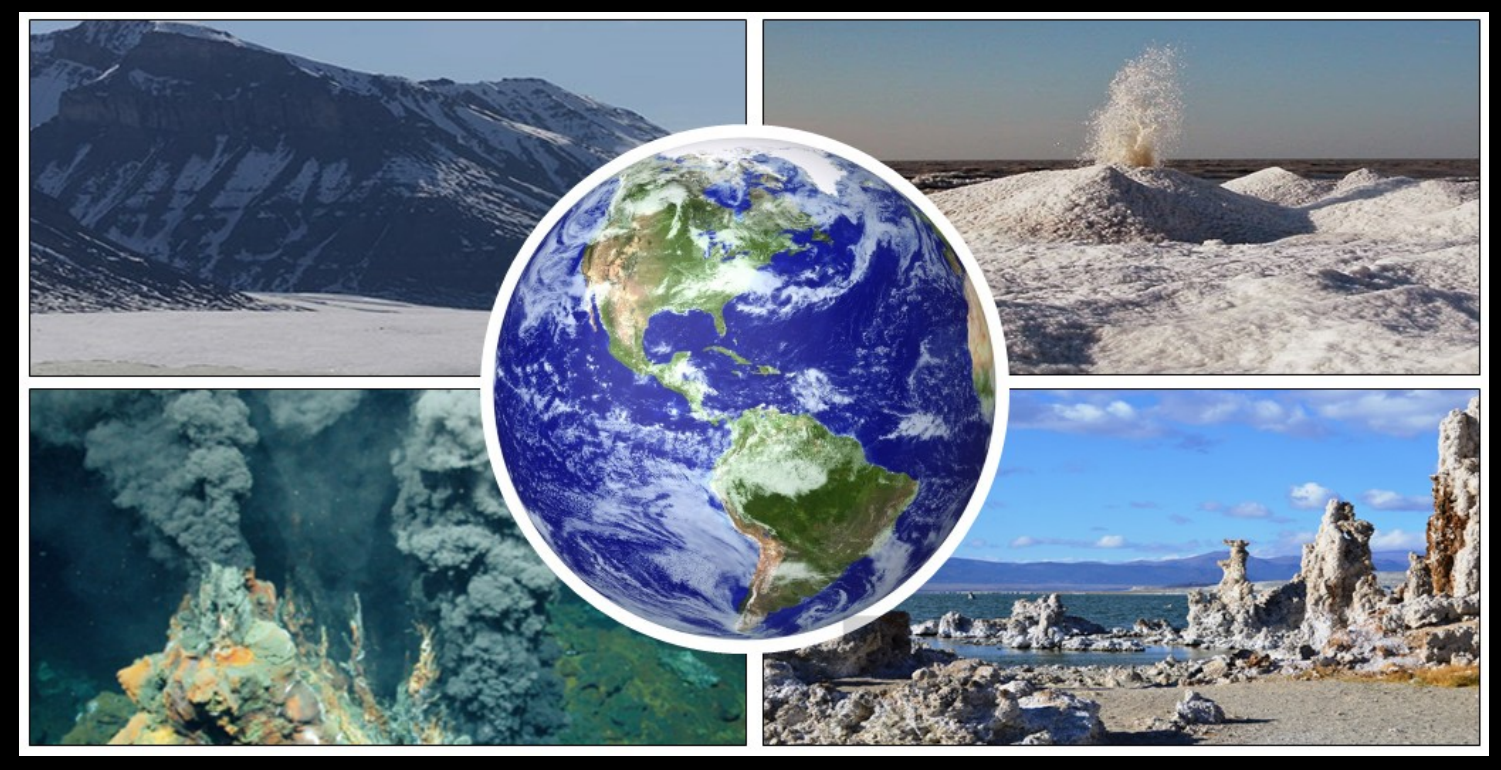

\title{
Building Consensus, Collaboration, and Capability for Ocean Worlds Field Science
}

Submitted by: Jennifer Stern Margaret Weng Heather Graham Jeffrey Bowman Stanford Hooker Marc Neveu Lynnae Quick Caitlin Ahrens

Endorsed by:

Bethany P. Theiling

Pablo Sabron

Victoria Da Poian

Nicole Wagner

Xiang Li

Eric Anslyn

Shane Byrne

Conor Nixon

Krista Soderland

Andrew Steele

Christopher H. House

Veronica Allen

Michael Malaska

Natalie Grefenstette

John Spear

Dina M. Bower

Mariam Naseem

Peter Willis

Roland Hatzenpichler Joe P. Renaud
NASA GSFC

SETI

NASA GSFC/SURA

Georgetown University NASA GSFC/UMBC

University of Texas Austin

University of Arizona

NASA GSFC

University of Texas Austin

Carnegie Institute

Pennsylvania State University

NASA GSFC/USRA

JPL/Caltech

Sante Fe Institute

Colorado School of Mines

NASA GSFC/UMCP

Space Generation Advisory

Council

JPL/Caltech

Montana State University

NASA GSFC/USRA

\author{
NASA Goddard Space Flight Center (GSFC) \\ Georgetown University \\ NASA GSFC/Catholic University of America \\ University of California, San Diego \\ NASA GSFC \\ NASA GSFC \\ NASA GSFC \\ University of Arkansas
}

Morgan L. Cable
Laura Ratliff
Svetlana Shkolyar
Sarah Fagents
Brandi Kiel Reese
Tristan Caro
Chad Pozarycki
Stefani Milam
Antonio J. Ricco
Bob Dziak
Mäeva Millan
Catherine Walker
Thomas Bristow
Anais Roussel
Leroy Cronin
G. Matthew Fricke
Anurup Mohanty
Julie Bevilacqua
Jennifer Eigenbrode
Lou Chou

JPL/Caltech

Georgetown University

NASA GSFC/USRA

University of Hawaii

Dauphin Island Sea Lab

University of Colorado, Boulder

NASA GSFC/SURA

NASA GSFC

NASA Ames Research Center NOAA/PMEL

NASA GSFC/Georgetown University

NASA GSFC/UMD/WHOI

NASA Ames Research Center

Georgetown University

University of Glasgow

University of New Mexico

SRM Institute of Science and

Technology

Georgetown University

NASA GSFC

NASA GSFC/Georgetown University 


\section{EXECUTIVE SUMMARY}

Field work provides unique information to address decadal science questions relevant to Ocean Worlds.

Consensus. We advocate for a more active role by NASA in building consensus in the planetary science and astrobiology communities to identify high value terrestrial Ocean World analog sites. We support a workshop activity analogous to the effort performed for the Mars community (Hipken et al., 2013) to develop a rubric to evaluate Ocean Worlds Field Sites, with specific consideration of lower fidelity, but more accessible sites.

Collaboration. We advocate for more ample and efficient mechanisms for astrobiology and planetary science researchers to collaborate with fellow scientists interested in these analog sites, including increasing partnerships and aligning goals with other federal agencies such as NSF and NOAA.

Capability. We advocate for common repositories similar to oceanographic data repositories to enhance data sharing, creation of physical sample archives (e.g., Antarctic Meteorite Curation) to promote access to field samples for a broad range of scientists, and improved research infrastructure including long term environmental monitoring at field sites to maximize the amount of data gathered during a field expedition and increase opportunities for a broader range of scientists.

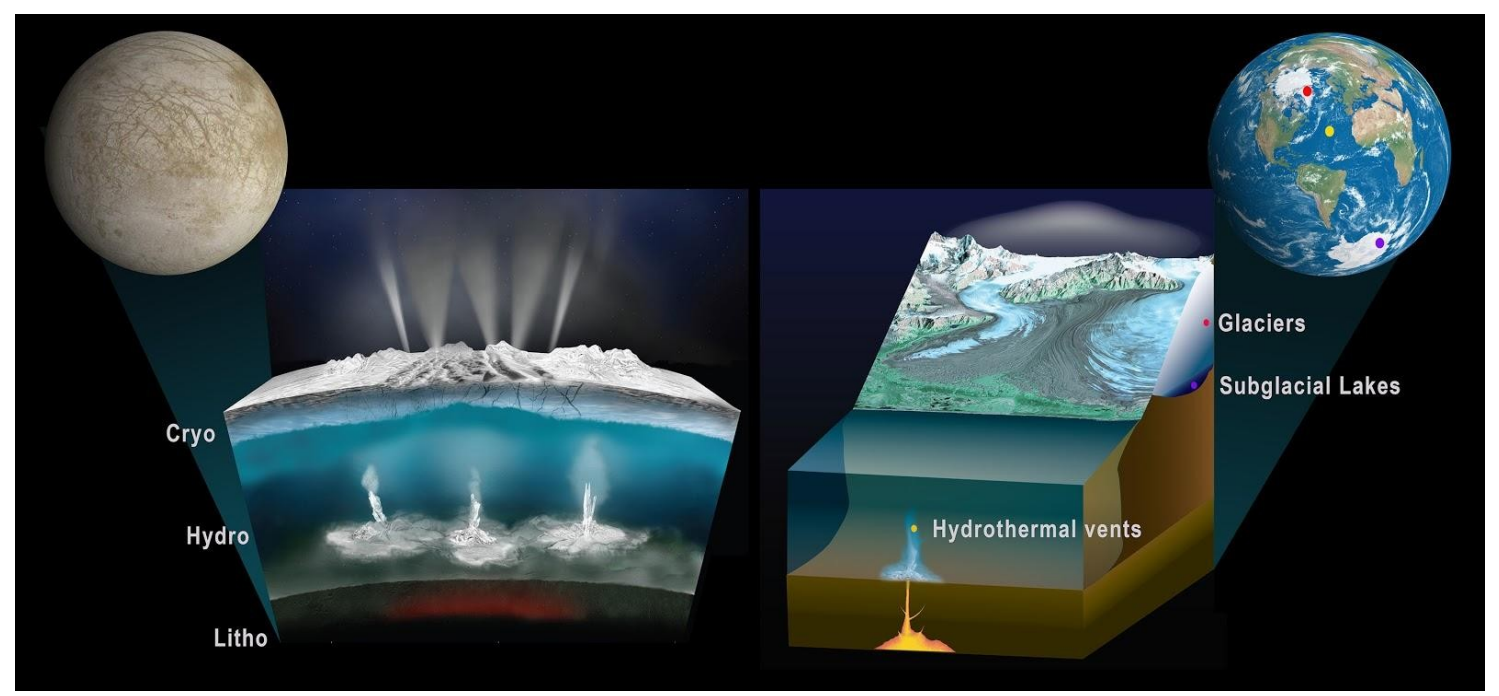

FIGURE 1. Multiple terrestrial analog field sites have been proposed to model Ocean Worlds environments. Many of these are costly and complicated to access, making Ocean Worlds field work accessible only to large, well-funded institutions, and limiting the range of scientists and institutions that can participate.

\section{THE CRITICALITY OF FIELD WORK FOR OCEAN WORLDS RESEARCH}

Our understanding of Ocean and Icy Worlds in our solar system is built on the scaffolding of oceanographic and cryospheric work conducted in the field by Earth Scientists. Because of this, 
field studies at terrestrial analog sites represent an important contribution to the science of Ocean and Icy Worlds. While planetary scientists approach field work at these sites with a different objective than our Earth sciences counterparts, there is significant overlap between planetary science studies of terrestrial analogs and Earth science, and collaboration between these disciplines can only advance our understanding and the science of ocean and icy worlds more effectively.

Because we are constrained by the limited cadence of exploration missions to outer solar system destinations, addressing high priority science questions as defined by the previous Decadal Survey requires a combination of approaches including analysis of mission data, computational modeling, laboratory work, and field observations at terrestrial analogs. Scientific expeditions to analog sites represent the opportunity to conduct experiments within a wide variety of co-occurring parameters. These large and variable parameter interactions common in nature are often dictated by feedback conditions that are either unknown or incredibly difficult to describe and therefore either challenging or impossible to simulate in a laboratory setting. From a mission concept and operations standpoint, field campaigns offer a useful testbed for exploring the impact of resource limitation on science return. Additionally, both field work and missions operate under a certain level of risk, so measurement strategies and payloads need to account for potential failure of an instrument, or the inability to collect a desired sample, and be prepared to adapt other measurements or targets to achieve the desired science. Finally, experimentalists also look to terrestrial analog environments to validate their experimental design.

In order to fully realize the potential for field work to help unravel outstanding high priority science questions for Ocean Worlds, we need to 1) coordinate the planetary science and astrobiology community to reach consensus on high value terrestrial Ocean World analog sites, 2) more effectively partner with colleagues who specialize in these terrestrial environments and 3) organize data, samples, and access to these environments to maximize science yields from field work. To connect these scientific research goals to the current Ocean Worlds exploration environment we explore these themes within the context of the previous Decadal Survey.

\section{DECADAL SCIENCE QUESTIONS FOR OCEAN WORLDS}

The most recent Decadal Survey specifies a Flagship class Jupiter/Europa Orbiter to explore habitability of Europa as a high priority mission, which will be fulfilled by the Europa Clipper Orbiter launching in 2024. The Decadal also features Europa and other icy moons as targets for study to address top-level high priority questions in Planetary Science about the origins of the giant planets and their satellite systems, organic synthesis, habitability, and chemical/physical processing and identifies priority science questions for Outer Planets Satellites. Table 1 lists the top-level science questions for Outer Planets Satellites posed in the last Decadal survey. To emphasize the importance of field work at terrestrial analog sites we have included references to specific investigations that address these science questions.

Field work is an effective way to address questions focusing on the physical processes that shape the surfaces of satellites, and the conditions for habitability in icy environments. In some cases, analog investigations may obliquely address these top-level questions by providing model environments to test methodology (such as extraction of volatiles from ices). In other 
cases, analog investigations may directly address a given question, as in the case of studying chemosynthesis in deep water, deep ice, or deep Earth environments to understand the energetic requirements for sustaining life.

Table 1. Decadal Science questions where field work can make a significant contribution to the state of knowledge.

\begin{tabular}{|c|c|c|}
\hline Decadal Science Question & Secondary Question & Analog Investigation \\
\hline \multirow{3}{*}{$\begin{array}{l}\text { How did the satellites of } \\
\text { the outer solar system } \\
\text { form and evolve? }\end{array}$} & $\begin{array}{l}\text { What determines the abundance and } \\
\text { composition of satellite volatiles? }\end{array}$ & $\begin{array}{l}\text { Improving remote and in situ detection strategies for } \\
\text { volatiles, understanding the role of clathration in volatile } \\
\text { transport }\end{array}$ \\
\hline & $\begin{array}{l}\text { How are satellite thermal and orbital } \\
\text { evolution and internal structure related? }\end{array}$ & Understanding the formation of terrestrial ice volcanoes \\
\hline & $\begin{array}{l}\text { What is the diversity of geologic activity } \\
\text { and how has it changed over time? }\end{array}$ & \multirow{2}{*}{$\begin{array}{l}\text { Studying evolution of terrestrial volcanic domes, caldera } \\
\text { collapse and resurgence, pingo and pit chain formation, } \\
\text { and geysering hotspots. Studying frazil ice, glacial ice } \\
\text { streams, and lava flows analogs for cryovolcanism. } \\
\text { Understanding processes in terrestrial ice through } \\
\text { monitoring subglacial eruptions and glacial outburst } \\
\text { floods, field seismology on ice sheets/glaciers }\end{array}$} \\
\hline \multirow{2}{*}{$\begin{array}{l}\text { What processes control } \\
\text { the present-day behavior } \\
\text { of these bodies? }\end{array}$} & $\begin{array}{l}\text { How do active endogenic processes } \\
\text { shape the satellites' surfaces and } \\
\text { influence their interiors? }\end{array}$ & \\
\hline & $\begin{array}{l}\text { How do exogenic processes modify these } \\
\text { bodies? }\end{array}$ & $\begin{array}{l}\text { Studying evolution and structure of impact craters. } \\
\text { Understanding mechanisms of and landforms created by } \\
\text { glacial erosion }\end{array}$ \\
\hline \multirow{4}{*}{$\begin{array}{l}\text { What are the processes } \\
\text { that result in habitable } \\
\text { environments? }\end{array}$} & $\begin{array}{l}\text { Where are subsurface bodies of liquid } \\
\text { water located, and what are their } \\
\text { characteristics and histories? }\end{array}$ & $\begin{array}{l}\text { Detection and mapping of subglacial waters, isotopic and } \\
\text { geochemical studies of subglacial lakes, understanding } \\
\text { material and energy exchange between subglacial water } \\
\text { and surface ice }\end{array}$ \\
\hline & $\begin{array}{l}\text { What are the sources, sinks, and } \\
\text { evolution of organic material? }\end{array}$ & $\begin{array}{l}\text { Studying organics, microbial communities, and carbon } \\
\text { cycling in hydrothermal systems, subglacial lakes, and ice }\end{array}$ \\
\hline & $\begin{array}{l}\text { What energy sources are available to } \\
\text { sustain life? }\end{array}$ & $\begin{array}{l}\text { Investigating low energy limits of life on Earth and survival } \\
\text { strategies for oligotrophic habitats, e.g. chemosynthesis in } \\
\text { deep water, deep subsurface communities, subglacial } \\
\text { communities }\end{array}$ \\
\hline & $\begin{array}{l}\text { Is there evidence for life on the } \\
\text { satellites? }\end{array}$ & $\begin{array}{l}\text { Measuring gradients of life in deep ocean, hydrothermal, } \\
\text { and glacial locations. Understanding the limits of life in } \\
\text { extreme conditions of temperature, pressure and osmotic } \\
\text { stress }\end{array}$ \\
\hline
\end{tabular}

\section{Moving ForWARD: Consensus, Collaboration, CAPABILITY}

\section{COMMUNITY CONSENSUS}

Analog field work must begin with a focus on addressing a specific high-level question. The value and impact of field work at terrestrial analogs are both maximized when the limitations of the chosen site are well understood. Currently, there is no widely accepted rubric for evaluating the fidelity of an analog site and its usefulness in modelling the conditions on Ocean Worlds. Instead, there are a small number of high-fidelity sites that are widely publicized and used, such as subglacial lakes in Antarctica or the Lost City hydrothermal vents, and a larger number of more obscure sites that are less rigorously evaluated. This creates a high demand for 
the "gold standard" field sites that are also often restricted and remote, and structurally disadvantages researchers early in their careers or with less funding, who are less likely to be able to access these locations.

The Ocean Worlds community must discuss and negotiate which important qualities of a terrestrial analog should claim biological, chemical and physical fidelity to Ocean Worlds. More agreement is needed on the degree of fidelity required to address relevant decadal questions relevant to Ocean Worlds. We call for not only a more rigorous evaluation of intriguing remote sites, but also new considerations of low-fidelity but more accessible sites. For example, the sampling of high-altitude lakes in the western US that freeze over during winter might be attractive alternatives to high-demand "gold standard" field sites such as Antarctic subglacial lakes. The use of local or regional sites will likely allow for more nimble (i.e., low cost) field work. How might we answer questions about other planets using the ordinary materials of our own backyards? This question is even more relevant given current Coronavirus travel restrictions and concerns. Given that travel will likely be significantly more problematic than in the past, at least for some part of our foreseeable future, the use of local or regional sites requiring much smaller numbers of individuals could be a significant advantage over "gold standard" sites that traditionally have relied on moving a larger groups of researchers.

Additionally, the Ocean Worlds community must recognize that there are few, if any, good analog sites on Earth for many of the unique locales on Icy and Ocean Worlds. Strategies to recognize and remediate these differences require the community effort to apply our knowledge of these systems and agree on how to justify these limitations. We advocate for NASA to take an active role in helping to build consensus in the community, such as supporting a workshop like the one conducted by Mars researchers (Hipkin et al., 2013) to help define the adequacy of analog field sites.

\section{CROSS-DISCIPLINE COLLABORATION}

Many useful planetary analog sites are also studied in the context of geology, ecology, or environmental science. It is crucial we identify the "big questions" in Ocean Worlds science that field work can uniquely help answer, and enlist the expertise of our colleagues in oceanography, glaciology, geology, and in other fields in the natural sciences who may be local partners or longtime investigators of desired field analog sites. Forming collaborations with investigators outside of astrobiology and planetary science is vital for gaining a fuller understanding of processes and habitability on other worlds. We advocate for more ample and efficient mechanisms for astrobiology and planetary science researchers to collaborate with fellow scientists interested in these analog sites. This goal aligns with efforts to increase partnerships with other agencies and foundations as well, as outlined in the Astrobiology Strategy Survey (Chapter 5; Leveraging Partnerships, https://www.ncbi.nlm.nih.gov/books/NBK540099/). Improved mechanisms for cross-discipline collaboration are especially urgent for oceanographic analog research. There is but one ocean world that we can readily access, and it is the world that NASA is least equipped to study except from orbit. Access to community resources such as ships are essential to carry out the needed analog studies. Although NASA-funded work is routinely carried out onboard UNOLS vessels (operated by various institutions on behalf of NSF) and private vessels (e.g., the Falkor owned and operated by the Schmidt Ocean Institute), the allocation of these resources is costly and 
haphazard. We encourage NASA to increase collaboration with NSF and NOAA to identify new ways to acquire ship time for analog studies.

\section{ENHANCING CAPABILITY}

Mounting a large-scale investigation at many Ocean Worlds field sites is complicated by their remote nature and the need for extensive logistics, specialists, and safety precautions - all of which are costly. For example, Antarctic research is only a possibility for an elite few due to its expense and relatively small number of funding opportunities. While we recognize that remoteness of field sites is a fixed quality, we advocate for increasing accessibility by also improving data- and sample-sharing architecture. It is increasingly important to maximize every sampling opportunity in remote locations. First, Ocean Worlds analog science must devise a way to organize and share data from previous expeditions in a common repository, which would invite participation remotely and enable more comprehensive meta-analyses. For example, the Astrobiology Habitable Environments Database (AHED), is a recently developed platform designed to consolidate and promote access to astrobiology datasets. A similar Ocean Worlds-specific repository should look to AHED's findings and best practices for guidance (see "A Strategy for Managing NASA's Long Tail of Planetary Research Data. Insights from the Development of the Astrobiology and Habitable Environments Database (AHED)" by Bristow et al., submitted to this Decadal Survey). Second, we propose creation and maintenance of physical sample archives, which would promote access to valuable field samples. Finally, we advocate for improved research infrastructure at field sites, which would increase access and maximize the amount of data gathered during a field expedition.

The Ocean Worlds research community should model archiving and data-sharing efforts on existing resources organized by other fields, listed in Table 2. Online databases and datasharing are commonly used in many disciplines, and these provide a centralized and searchable way to access published data. Physical sample archives have also been implemented in a variety of fields, especially paleoclimatology, which relies on physical climate proxies to address research questions. The Antarctic Meteorite Curation program, maintained by JSC, is another successful example. Not only would sample archives potentially reduce demand for highly restricted sites, but centralized sample sharing would encourage participation in analog science from researchers without the funds to mount a field campaign individually. In fact, efficiently sharing data and samples collected in unique analog field sites will also serve to preserve their utility for years to come by reducing impact on these distinctive environments.

The marine and terrestrial ecology and geology communities carry out several research initiatives that offer guidance for interdisciplinary analog studies. These include efforts to collect and curate samples on behalf of the community, and to continue long-term observations beyond the reach of an individual lab or small group of investigators. The International Ocean Discovery Program (IODP, formerly the Integrated Ocean Drilling Program) - which has considerable participation from the planetary geology and astrobiology communities - provides a sample collection and curation platform. IODP maintains a specialized research vessel, the JOIDES Resolution, to carry out ocean drilling projects on behalf of a broad user community. Physical samples are stored and curated at repositories at multiple institutions in the US, Germany, and Japan. IODP coring activities are controlled by a Science Evaluation Panel which reviews proposals from the community. 
Table 2. Examples of infrastructure for data-sharing, sample collection and field research currently in use by other disciplines.

\begin{tabular}{|c|c|c|}
\hline Organization & Description & Format \\
\hline $\begin{array}{l}\text { Antarctic meteorite curation } \\
\text { https://curator.jsc.nasa.gov/antmet/ } \\
\text { index.cfm }\end{array}$ & $\begin{array}{l}\text { Collection expeditions, processing and storage } \\
\text { of Antarctic meteorites for scientific study }\end{array}$ & Physical archives \\
\hline $\begin{array}{l}\text { Integrated Ocean Drilling Program } \\
\text { (IODP) https://iodp.org/ }\end{array}$ & $\begin{array}{l}\text { Scientific collaboration for study of ocean } \\
\text { seafloor sediments, facilitates access to } \\
\text { sampling, archives data and samples from } \\
\text { expeditions }\end{array}$ & $\begin{array}{l}\text { Research infrastructure, physical } \\
\text { archives, digital database }\end{array}$ \\
\hline $\begin{array}{l}\text { Long Term Ecological Research } \\
\text { Nework (LTER) https://Iternet.edu/ }\end{array}$ & $\begin{array}{l}\text { Supports long-term and large-scale ecological } \\
\text { research at } 28 \text { sites, including the McMurdo } \\
\text { Dry Valleys, provides open access to } 40 \text { years } \\
\text { of data collection }\end{array}$ & $\begin{array}{l}\text { Collaborative research network, } \\
\text { field research infrastructure, } \\
\text { digital database }\end{array}$ \\
\hline $\begin{array}{l}\text { National Ecological Observatory } \\
\text { Network (NEON) } \\
\text { http://criticalzone.org/national/ } \\
\end{array}$ & $\begin{array}{l}\text { Continental-scale observation facility ecological } \\
\text { research observatory collecting long-term open } \\
\text { access ecology data at } 81 \text { field sites }\end{array}$ & $\begin{array}{l}\text { Collaborative research network, } \\
\text { field research infrastructure, } \\
\text { digital database }\end{array}$ \\
\hline $\begin{array}{l}\text { Critical Zone Collaborative Network } \\
\text { (formerly Critical Zone } \\
\text { Observatories) }\end{array}$ & $\begin{array}{l}\text { Nine observatories with research } \\
\text { infrastructure, research collaboration } \\
\text { opportunities, virtual dataset management }\end{array}$ & $\begin{array}{l}\text { Collaborative research network, } \\
\text { research infrastructure, physical } \\
\text { archives, digital database }\end{array}$ \\
\hline $\begin{array}{l}\text { Smithsonian Research Centers } \\
\text { https://www.si.edu/ResearchCenters }\end{array}$ & $\begin{array}{l}\text { Facilitating scientific collaboration and access } \\
\text { to materials via sample archives, literature } \\
\text { databases, and field research stations with } \\
\text { infrastructure support }\end{array}$ & $\begin{array}{l}\text { Research infrastructure, digital } \\
\text { database, physical archives }\end{array}$ \\
\hline $\begin{array}{l}\text { World Data Center for } \\
\text { Paleoclimatology } \\
\text { https://www.ncdc.noaa.gov/data- } \\
\text { access/paleoclimatology-data/about- } \\
\text { the-paleoclimatology-program }\end{array}$ & $\begin{array}{l}\text { World's largest archive of climate and } \\
\text { paleoclimatology data. Contains proxy data, } \\
\text { climate data, information on physical sample } \\
\text { repositories, and more. }\end{array}$ & Digital database \\
\hline $\begin{array}{l}\text { Europlanet } \\
\text { https://www.europlanet- } \\
\underline{\text { society.org/europlanet-2024-ri/ }}\end{array}$ & $\begin{array}{l}\text { Access to field sites or laboratories for } \\
\text { European researchers via the Transnational } \\
\text { Access program, digital database for some } \\
\text { astronomical data }\end{array}$ & $\begin{array}{l}\text { Digital database, field research } \\
\text { infrastructure }\end{array}$ \\
\hline $\begin{array}{l}\text { NSF Ice Core Facility } \\
\text { https://icecores.org/ }\end{array}$ & $\begin{array}{l}\text { Curation, storage and study of meteoric ice } \\
\text { cores from global expeditions }\end{array}$ & $\begin{array}{l}\text { Physical archive. Data from } \\
\text { published studies available online }\end{array}$ \\
\hline $\begin{array}{l}\text { National Snow and Ice Data Center } \\
\text { https://nsidc.org/ }\end{array}$ & $\begin{array}{l}\text { Management and distribution of data about } \\
\text { the cryosphere, facilitates access and } \\
\text { collaboration }\end{array}$ & Digital database \\
\hline
\end{tabular}

The National Ecological Observatory Network (NEON) illustrates a second useful model. NEON is designed to provide data on how ecosystems are changing over time to the widest possible community. Observations of temporal variability is a luxury not afforded to much of the planetary science community, which often measures the cadence of new observations on decadal or longer timescales. This makes temporal sampling of Earth analogues that much more significant. Physical, chemical, and biological environmental features change on scales from minutes to years, having a huge impact on habitability, our ability to estimate habitability, and the possible distribution of biomarkers and extant life. Understanding this variability to the extent possible on Earth is necessary to interpret putative habitats on other planets. Another benefit of long-term observations is that temporal variability is a useful proxy for spatial variability, which can be difficult to measure on the desired scale. A major benefit to NEON on 
similar programs (e.g., the LTER program) is the contextual data they provide to projects funded independently. Proposals from a single investigator or small team of investigators (as from the Habitable Worlds or Exobiology Programs) can leverage data they would be unable to collect within the time or budget afforded their effort. A similar effort at key analog sites would radically change how the community studies interactions between the biosphere and geosphere, potentially leading to new models and methods for planetary exploration and life detection.

Central archives and data management capabilities are an important and well-meaning effort that has been legislated at the executive level. While we support the intention of these efforts, the fact is that this activity lacks any financial backing or infrastructure. By default, the resources needed for these activities are funded on the backs of science funding by incorporation as a line item into data management plans in every research and analysis proposal. We believe a centralized mechanism to provide for these services will benefit science research by no longer requiring $R \& D$ budgets that are stretched thin to accommodate archival expenses as well. Further, a centralized system will create a more equitable scientific landscape by allowing researchers with smaller funding capabilities and profiles at smaller institutions or in the developing world access to data and samples from planetary field analog sites that require considerable time, equipment, and financial resources to collect.

Finally, we encourage the development of improved and maintained research infrastructure at field sites to maximize data collection opportunities during costly field expeditions. We are encouraged by organizations like the National Critical Zone Observatories (succeeded by the Critical Zone Collaborative Network in Nov. 2020). The nine observatories maintained by the CZO provide instrumentation and ongoing measurements which are accessible to participating scientists. This greatly reduces the cost barrier for field campaigns while increasing the range of measurements and historical data collection available at a given site. Furthermore, data generated by CZO projects is available in online databases, facilitating future collaboration. We believe that more equitable, centralized organization of field work resources, as well as community consensus on the merits of ocean world analog sites, is vital to propel our scientific discoveries into the next decade of exploration.

\section{REFERENCES}

Hipkin, V.J., Voytek, M.A., Meyer, M.A., Léveillé, R. and Domagal-Goldman, S.D., 2013. Analogue sites for Mars missions: NASA's Mars Science Laboratory and beyond-Overview of an international workshop held at The Woodlands, Texas, on March 5-6, 2011.

National Academies of Sciences, Engineering, and Medicine; Division on Engineering and Physical Sciences; Space Studies Board; Committee on Astrobiology Science Strategy for the Search for Life in the Universe. An Astrobiology Strategy for the Search for Life in the Universe. Washington (DC): National Academies Press (US); 2018 Oct 10. 7, Leveraging Partnerships. Available from: https://www.ncbi.nlm.nih.gov/books/NBK540099/

National Research Council. 2011. Vision and Voyages for Planetary Science in the Decade 20132022. Washington, DC: The National Academies Press. https://doi.org/10.17226/13117. 